\title{
Coverage with vitamin A oil supplementation and factors influencing its uptake among children residing in an urban slum in Kolkata
}

\author{
Dr. Sonali Sain, MD1, Dr. Prianka Mukhopadhyay, MD1, Dr. Tushar Kanti Saha, MD¹, Dr. Ritu Ghosh, MD² \\ ${ }^{1}$ Dept. of Community Medicine, NRS Medical College, Kolkata \\ ${ }^{2}$ Dept. of Community Medicine, R.G.Kar Medical College, Kolkata
}

\section{ABSTRACT}

\begin{abstract}
Vitamin A oil supplementation of under-five children has been an effective strategy in reducing nutritional blindness and other childhood morbidity and mortality. The present cross-sectional study was undertaken to assess the coverage and factors influencing its uptake among 60-72 months old children residing in an urban slum in Kolkata. Out of 150 children only 61 (40.7\%) had completed all 9 doses of vitamin A while immunization was up-to-date in a substantially higher $(96.0 \%)$ proportion of children. Incomplete dosage of vitamin A oil were found to be higher in females, birth order above 2, families with low per capita income and poor nutritional status of the child. The association between maternal education and knowledge about dietary source was found to be statistically significant $\left(\chi^{2}=15, p<0.05\right)$. Diet survey revealed inadequate intake in the majority (70.7\%). Inadequate supply and lack of awareness were the two most common reasons of non compliance. More efforts are needed to ensure availability and awareness regarding vitamin A oil supplementation, promote dietary diversification and monitoring of health workers to prevent both under and overprescription with vitamin A oil.
\end{abstract}

Key Words: Coverage, Compliance, Vitamin A supplementation

\section{INTRODUCTION}

Vitamin A is an essential micronutrient necessary for important biological functions like maintaining normal vision, immune function, skeletal growth and integrity of glandular and epithelial tissue. Vitamin A deficiency (VAD) still remains a public health concern in developing countries like India. Subclinical VAD is much more common, though the actual prevalence is uncertain owing to a paucity of reliable national level data. ${ }^{[1]}$ Well designed scientific studies have clearly demonstrated the far reaching adverse health outcomes of Vitamin A deficiency. ${ }^{[2]}$ A survey in five north-eastern states (Assam, Bihar, Orissa, West Bengal and Tripura) showed the

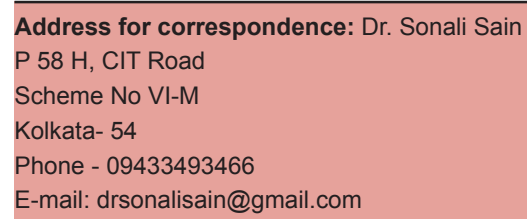

DOI: $10.5530 /$ ijmedph.4.2011.8 prevalence of Bitot's spots to be $0.7-2.2 \%$ and that of night blindness $1.2-4.0 \%$, indicating VAD to be a public health problem in all the five states. ${ }^{[3]}$ Government of India launched a national programme to address this issue way back in 1972 by administering massive doses of Vitamin A supplementation to all children under 36 months under the Expanded Programme of Immunization (EPI) which has been currently extended upto 60 months. This has been a cost effective strategy in reducing not only the burden of blindness but also severe childhood infections like diarrhea, complications of measles etc. However despite the existence of such an effective programme running in the country, statistics indicate that compliance to Vitamin A supplementation among 12-35 months old is very low with an average of only $21.0 \%(22.7 \%$ in urban and $20.4 \%$ in rural areas). ${ }^{[4]}$

\section{OBJECTIVES}

1. To assess the coverage of Vitamin A supplementation among children aged between 5-6 years living in an urban slum in Kolkata and 
2. To identify the risk factors and adverse outcomes related to partial or non compliance of Vitamin A supplementation.

\section{MATERIALS AND METHODS}

\section{Study design and sampling}

A community based descriptive type of study was conducted among 150 children aged between 60 months -72 months residing in an urban slum area in Chetla, Kolkata from March - May 2008. This area falls under the urban field practice area of All India Institute of Hygiene and Public Health, Kolkata. It has an estimated total population of 1.34 lakhs (Urban Health Centre Statistics 2003-2004). This area is divided into four sectors and one sector was selected by simple random sampling which had a population of 25,000 . The target population included all children aged between 60 months -72 months residing in that sector during the study period. The sample size was calculated to be 138 assuming a coverage with Vitamin A of $41.2 \%$ (West Bengal, NFHS III), 95\% confidence and $20 \%$ allowable error $\left(\mathrm{N}=\mathrm{Z}^{2} \mathrm{PQ} / \mathrm{L}^{2}\right)$. From the family folders maintained by the health centre, a sampling frame of all children between 60 months -72 months age group was prepared. It was found that 268 children in that slum belonged to the target age group. The required numbers of children were selected by simple random sampling from the family folder. Home visits were made and the purpose of the study was explained to the mothers/guardians and their informed verbal consent to participate in the study was obtained. Altogether 158 children were approached and the final sample size came to be 150 children after excluding incomplete data and those who did not give consent.

\section{Data collection}

Data collection was done using a pre-designed, pretested schedule containing questions pertaining to sociodemographic characteristics, immunization status, Vitamin A oil supplementation, nutritional status, morbidity profile in last one month and intake of Vitamin A rich foods in last one week. The schedule was translated into local language (Bengali) and used to interview the mothers/guardians. Immunization status and Vitamin A supplementation was verified from the immunization card of the child. Weights of the children were recorded by digital weighing machine and weight was categorized by $\mathrm{Z}$ score. Information on morbidity was collected by interviewing the mothers. A four-week history of morbidity symptoms including any episodes of acute respiratory infections, diarrhoea and history of measles in last 6 months was noted. In patients with a history of measles, the date of its occurrence was recorded. The children were clinically examined for signs and symptoms of Vitamin A deficiency in eyes, skin. Systemic examination was done to exclude any cardio respiratory and abdominal pathology.

Mothers were enquired about their knowledge regarding plant and animal sources of Vitamin A rich foods, symptoms and signs of deficiency and intake of prophylactic Vitamin A oil supplementation of their children. Data regarding vitamin A oil supplementation was verified from immunization card.

\section{Data analysis}

Collected data were then analyzed and statistical test were done with the help of Microsoft Excel \& Epi-info (3.5.1) software. Test for the statistical significance was applied by using $\chi^{2}$ test for analyzing the difference between two proportions $(P<0.05$ was considered significant).

\section{RESULTS}

Out of 150 children aged between 60-72 months, 63 $(42.0 \%)$ were boys and $87(58.0 \%)$ were girls. Only $40.7 \%$ children had completed all 9 doses of vitamin A. The proportion of children receiving incomplete doses of vitamin A oil was found to be higher in females and children belonging to joint family but was significantly greater in families with per capita income below Rs 500, illiterate mothers and malnourished children (Table 1).

Knowledge regarding plant \& animal sources, deficiency signs of vitamin A was found to be poorest in illiterate mothers and highest among mothers with secondary education and above. The association between maternal education and knowledge about at least one rich vegetarian (veg) and one rich non-vegetarian (non-veg) source of vitamin $\mathrm{A}$ was found to be statistically significant $\left(\chi^{2}=15.88, p<0.05\right)$. However knowledge about prevention of vitamin A deficiency was very low among all the groups. (Table2).

Frequency of dietary intake of vitamin A rich foods was reported to be $\leq 4$ days/week among majority $(78.6 \%)$ of the respondents. However a statistically significant association was observed between frequency of intake and awareness regarding dietary source of the vitamin (Table 3).

Occurrence of both acute respiratory infections (ARI) and malnutrition were significantly higher in children with incomplete vitamin A oil supplementation. Malnutrition, 


\begin{tabular}{|c|c|c|c|}
\hline Attributes & $\begin{array}{l}\text { Complete Vitamin A oil } \\
\text { status }(n=61)(40.7 \%)\end{array}$ & $\begin{array}{l}\text { Incomplete Vitamin A oil } \\
\text { status }(n=89)(59.3 \%)\end{array}$ & $X^{2}$ ( $p$ value) \\
\hline \multicolumn{4}{|l|}{ Sex } \\
\hline Female & $30(49.2)$ & $57(64.0)$ & 3.28 \\
\hline Male & $31(50.8)$ & $32(36.0)$ & $(0.07)$ \\
\hline \multicolumn{4}{|l|}{ Type of family } \\
\hline Nuclear & $44(72.1)$ & $61(68.5)$ & 0.22 \\
\hline Joint & $17(27.9)$ & $28(31.5)$ & $(0.63)$ \\
\hline \multicolumn{4}{|l|}{ Per capita income (Rs) } \\
\hline$<500$ & $27(44.2)$ & $56(62.9)$ & 6.63 \\
\hline $500-1000$ & $26(42.6)$ & $29(32.5)$ & $(0.03)$ \\
\hline$>1000$ & $8(13.1)$ & $4(4.4)$ & \\
\hline \multicolumn{4}{|l|}{ Birth order } \\
\hline$\leq 2$ & $46(75.4)$ & $67(59.3)$ & 0.00 \\
\hline$>2$ & $15(24.6)$ & $22(59.5)$ & $(0.98)$ \\
\hline \multicolumn{4}{|l|}{ Maternal education } \\
\hline Illiterate & $14(22.9)$ & $30(68.2)$ & 12.38 \\
\hline Primary \& Middle & $19(31.1)$ & $42(68.9)$ & $(0.00)$ \\
\hline Secondary \& above & $28(45.9)$ & $17(37.8)$ & \\
\hline \multicolumn{4}{|l|}{ Nutritional status } \\
\hline Normal & $18(29.5)$ & $11(12.4)$ & 6.82 \\
\hline$<-2$ z score & $43(70.5)$ & $78(87.6)$ & $(0.00)$ \\
\hline
\end{tabular}

\section{Table 2: Knowledge of mothers regarding Vitamin A according to their educational status}

\begin{tabular}{lccc}
\hline & \multicolumn{3}{c}{ Knowledge regarding Vitamin A } \\
\cline { 2 - 4 } Educational status of & $\begin{array}{c}\text { Source (at least 1 veg \& } \\
\text { mothers }\end{array}$ & $\begin{array}{c}\text { Deficiency signs/ } \\
\text { Symptoms (\%) }\end{array}$ & $\begin{array}{c}\text { Prevention of } \\
\text { deficiency status (\%) }\end{array}$ \\
\hline Illiterate $(n=44)$ & $4(9.1)$ & $1(2.3)$ & - \\
Primary \& Middle $(n=61)$ & $16(26.2)$ & $10(16.4)$ & - \\
Secondary \& above $(n=45)$ & $21(46.7)$ & $18(40.0)$ & $5(11.11)$ \\
$X^{2}$ & 15.88 & 20.87 & 12.33 \\
$(p$ value $)$ & $(0.00)$ & $(0.00)$ & $(0.00)$ \\
\hline
\end{tabular}

\begin{tabular}{|c|c|c|c|}
\hline \multirow{2}{*}{$\begin{array}{l}\text { Attributes } \\
\leq 4 / \text { week } \\
(n=118)(78.6 \%)\end{array}$} & \multicolumn{3}{|c|}{$\begin{array}{c}\text { Frequency of dietary intake of } \\
\text { vitamin A }\end{array}$} \\
\hline & $\begin{array}{c}>4 / \text { week } \\
(\mathrm{n}=32)(21.4 \%)\end{array}$ & $\begin{array}{c}x^{2} \\
p \text { value }\end{array}$ & \\
\hline \multicolumn{4}{|l|}{ Maternal education } \\
\hline Illiterate & $32(27.1)$ & $12(37.5)$ & 1.31 \\
\hline Literate & $86(72.9)$ & $20(62.5)$ & $(0.25)$ \\
\hline \multicolumn{4}{|c|}{ Knowledge about source } \\
\hline Known & $19(16.1)$ & $22(68.7)$ & 35.13 \\
\hline Not known & 99 (83.9) & $10(31.2)$ & $(0.00)$ \\
\hline \multicolumn{4}{|l|}{ Birth order } \\
\hline$\leq 2$ & $87(73.7)$ & $26(81.2)$ & 0.77 \\
\hline$>2$ & $31(26.3)$ & $6(18.7)$ & $(0.38)$ \\
\hline
\end{tabular}

diarrhea and ARI were all significantly associated with low frequency of dietary intake of vitamin A (Table 4).

Immunization schedule was upto date and completion of prophylactic doses of vitamin A supplementation was found to be higher in male children (Figure 1).
Diet survey by 24 hour recall method revealed inadequate level of vitamin A in diet in the majority (70.7\%) (Figure 2) Inadequate supply of Vitamin A oil was stated to be the most common reason of non-compliance to prophylactic supplementation (Figure 3).

2 children were found to have suffered from measles in the last 6 months. 2 children complained of night blindness, who were female children, malnourished, not immunized at all and migrated from the neighbouring state.

\section{DISCUSSION}

Reports from different trials conducted in vitamin A deficient population indicate that vitamin A deficiency (VAD) in children causes increased morbidity and mortality of infants and children, poor growth and possibly similar effects in infants infected with HIV. ${ }^{[5,6]}$ Despite steady progress in controlling vitamin A deficiency and an 


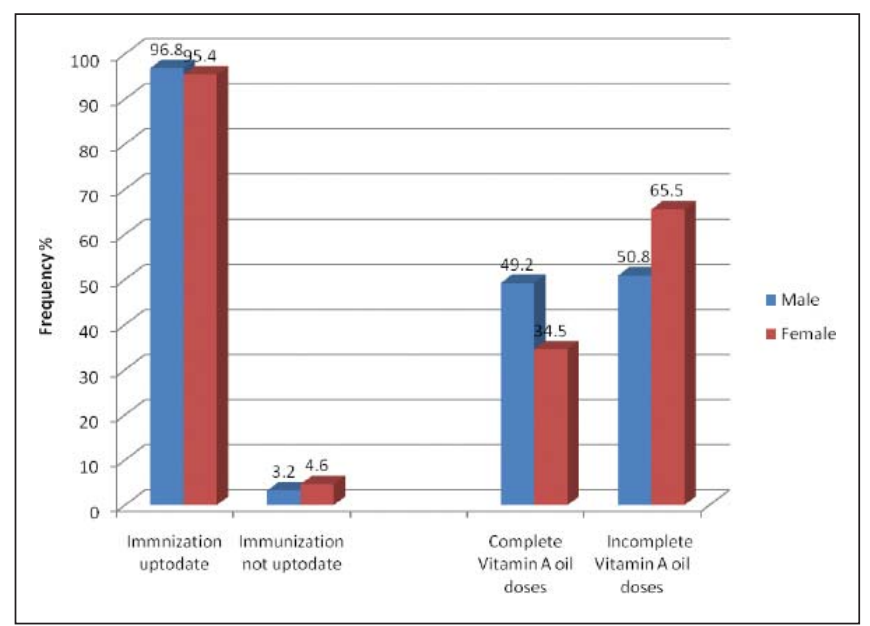

Figure 1: Sexwise distribution of immunization status \& vitamin A doses

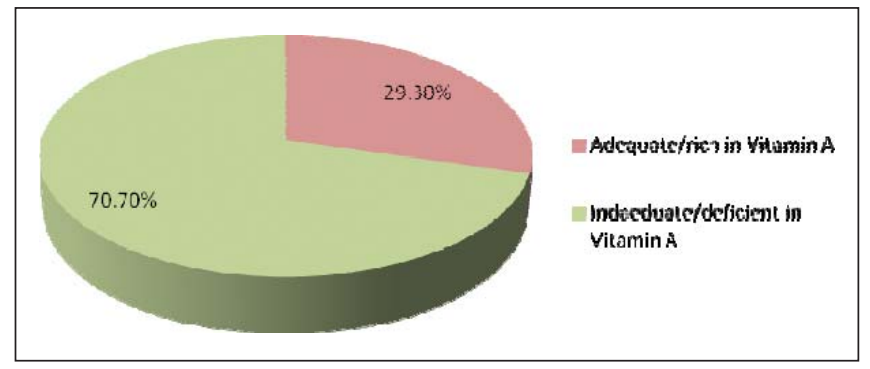

Figure 2: Vitamin A content in the diet absence of overt, global nutritional decline over the past 2 decades, the most recent estimates from the World Health Organization report that 190 million preschool children (almost 32\%) and nearly 20 million pregnant mothers (almost 10\%) are vitamin A-deficient in low-income countries. $^{[7]}$ At present the great majority of countries where VAD is known to be a major public health problem have policies supporting the regular supplementation of children, an approach of known large scale effectiveness that can reach the subpopulations affected by, or at risk of being affected by, VAD ${ }^{[1]}$ In Kolkata where the present study was conducted, the coverage with Vitamin A oil is only $18.7 \% .^{[4]}$ Various nutritional and health-related parameters, such as socioeconomic indicators, vitamin A intake and co-morbidities, have to be considered to identify the factors responsible for vitamin A deficiency. ${ }^{[8]}$ In the present study, the risk factors identified for incomplete dosage of vitamin A oil supplementation were lesser maternal educational status, families with low per capita income (PCI) and malnourished children. A survey in Bangladesh found higher birth order, female sex, poor socioeconomic status and low level of maternal education to be important sociodemographic risk factors for low coverage with vitamin A oil. ${ }^{[9]}$

\section{a Inadequatesupply a Noknowledge Inconvenient timing}

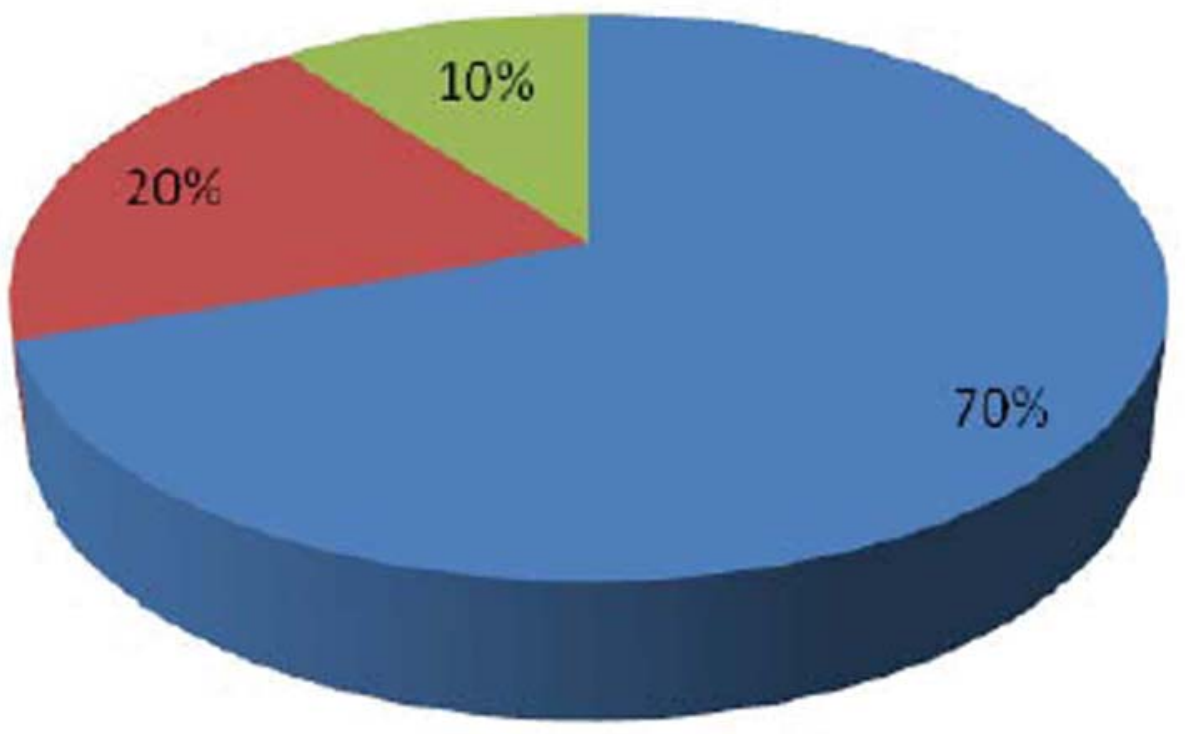

Figure 3: Commonest reasons of non-compliance to prophylacitic Vitamin A oi 


\begin{tabular}{|c|c|c|c|}
\hline Attributes & Malnutrition (\%) & Diarrhoea (\%) & ARI (\%) \\
\hline \multicolumn{4}{|l|}{ Doses of Vitamin A oil } \\
\hline Complete $(n=61)$ & $43(70.5)$ & $14(22.9)$ & $14(22.9)$ \\
\hline Incomplete $(n=89)$ & $78(87.6)$ & $27(30.3)$ & $45(50.5)$ \\
\hline$x^{2}$ & 6.82 & 0.99 & 12.27 \\
\hline ( $p$ value) & $(0.00)$ & $(0.31)$ & $(0.00)$ \\
\hline \multicolumn{4}{|c|}{ Dietary intake of Vitamin A } \\
\hline$\leq 4 /$ week $(n=118)$ & $100(84.7)$ & $20(16.9)$ & $55(46.6)$ \\
\hline$>4 /$ week $(n=32)$ & $21(65.6)$ & $11(34.4)$ & $4(12.5)$ \\
\hline$x^{2}$ & 5.9 & 4.66 & 12.27 \\
\hline ( $p$ value) & $(0.01)$ & $(0.03)$ & $(0.00)$ \\
\hline
\end{tabular}

The fact that a majority of the population subsists on inadequate diets, with vitamin $\mathrm{A}$ intakes less than half the recommended level and a significant proportion of children having clinical and sub-clinical deficiency is a matter of public health concern. ${ }^{[10]}$ Maternal education is a key factor determining awareness regarding dietary sources and also in achieving high coverage with vitamin A oil of their children. Coverage was found to be lower among mothers who were illiterate or from lower educational status. For the majority, dietary assessment revealed inadequate intake of vitamin A rich foods. Frequency of dietary intake was significantly poor among mothers who were unaware of the dietary sources. It is necessary to identify these vulnerable groups and educate mothers about the common, easily affordable rich dietary sources of the vitamin. Opportunity of visits to the immunization clinic may be utilized to counsel and motivate mothers regarding good dietary habits and completing vitamin A oil supplementation of their children. Promotion of family planning methods will enable couples to have small families and hereby provide more for their children.

Interestingly the present study revealed that though coverage with Vitamin A oil supplementation lagged behind considerably, immunization coverage was up-todate among a majority of the children in both sexes. In contrast studies in Bangladesh and Indonesia revealed a lower coverage with vitamin A among children who missed childhood immunizations. ${ }^{[1]}$ The commonest reason for non compliance in this study was stated to be non availability. This issue needs to be addressed urgently. It showed that though mothers were motivated to accept the services willingly but failure to provide the same came as a setback to the national programme.

Association between vitamin A deficiency and diseases is well documented. Studies have clearly shown that diarrhoeal disease and intestinal parasitoses affect vitamin A status by increasing loss of nutrients and reducing the absorption of nutrients. ${ }^{[12]}$ Another large study found mild vitamin A deficiency to be directly associated with at least $16 \%$ of all deaths in children aged from 1 to 6 years. ${ }^{[13]}$ Malnourished children are more likely to suffer from vitamin A deficiency disorders and have higher morbidity due to infectious diseases. A significant difference in the proportion of malnutrition was observed between children who did and did not complete vitamin A supplementation. This finding re-emphasizes the fact that children who are most likely to benefit from vitamin A supplementation are not being covered.

Vitamin A deficiency persists as a global nutrition problem that merits short-term, medium term and longterm prevention. These include promotion of breast feeding, vitamin A supplementation, fortification of dietary staples (commercial or food aid commodities), and homestead food production. ${ }^{[14]}$ In recent years, conflicting reports have been obtained regarding continuation of the vitamin A supplementation programme in favour of dietary measures, especially in the context of a marked reduction in the prevalence of keratomalacia. The most promising strategies focus on increasing the vitamin A supply by improving the diet and the diversity of food supply, which seems to be the most thorough and durable method and by enriching common foodstuffs with vitamin $A \cdot{ }^{[8]}$ As observed in this study the dietary intake of vitamin A was inadequate in majority of the study participants. It has been opined that under these circumstances where Vitamin A intakes of children are less than half the RDA and a significant proportion of them have clinical evidence of deficiency, it is not wise or ethical to withdraw the benefits of supplementation. ${ }^{[10]}$ Health workers need to be trained to counsel mothers about dietary diversification, identification of early signs of vitamin A deficiency and report adverse effects. They should also be monitored to prevent both under and overprescription with vitamin A oil. 


\section{ACKNOWLEDGEMENT}

We wish to convey our gratitude to Dr. Ranadeb Biswas, Professor \& Head, Dept. of PSM, All India Institute of Hygiene and Public Health, Kolkata and All the staffs of Urban Health Centre (UHC), Chetla, Kolkata, for the help they rendered in carrying out the study.

\section{REFERENCES}

1. Available from http://www.unsystem.org/SCN/archives/npp19/ch12.htm. [Last accessed on 02.05.11].

2. Demographic and health-related risk factors of subclinical Vitamin $A$ Deficiency in Ethiopia. Demissie T, Ali A, Mekonnen Y, Haider J, Umeta M. J Health Popul Nutr. 2009 October;27(5):666-673.

3. India Nutrition Profile, Ministry of Human Resource Development. Government of India, 1998.

4. Key indicators from NFHS III (2005-2006).Available from www.nfhsindia. org. [Last accessed on 02.05.11]

5. Beaton GH, Martorell R, Aronson KJ (1993). Effectiveness of vitamin A supplementation in the control of young childhood morbidity and mortality in developing countries. State-of-the-Art Series Nutrition Policy Discussion Paper No. 13. Geneva: ACC/SCN.
6. Daulaire NM, Starbuck ES, Houston RM, Church MS, Stukel TA, Pandey MR (1992) Childhood mortality after a high dose of vitamin A in a high risk population. British Medical Journal 304(6821):207-210.

7. World Health Organization. Global prevalence of vitamin A deficiency in populations at risk 1995-2005: WHO global database on vitamin A deficiency. Geneva : WHO; 2009.

8. Samba C, Gourmel B, Houze P, Malvy D. Assessment of vitamin a status of preschool children in a sub-saharan African setting: comparative advantage of modified relative-dose response test. $\mathrm{J}$ Health Popul Nutr 2010 Oct;28(5):484-493.

9. Semba RD, Pee S, Sun K, Akhter N, Martin W, Bloem MW, Raju VK. Coverage of vitamin A capsule programme in Bangladesh and risk factors associated with non-receipt of vitamin A. J Health Popul Nutr 2010 Apr;28(2):143-148.

10. Vitamin A Programme in India - Why the Controversy? Available from http://www.ifm.net/industry/vitamin a program.htm. [Last accessed on 02.05.11]

11. Berger SG, de Pee S, Bloem MW, Halati S, Semba RD. High malnutrition and morbidity among children who are missed by periodic vitamin A capsule distribution for child survival in rural Indonesia. J Nutr 2007;137:1328-33.

12. Curtale F, Pokhrel RP, Tilden RL, Higashi G. Intestinal helminths and xerophthalmia in Nepal. A case-control study. J Trop Pediat 1995;41: 334-7.

13. Sommer A, Tarwotjo I, Hussaini G, Susanto D. Increased mortality in children with mild vitamin A deficiency. Lancet. 1983;2:585-8.

14. West KP, Mehra S. Vitamin A intake and status in populations facing economic stress. J Nutr. 2010;140:201-7. 